\title{
Modes of ocean variability in the tropical Pacific as derived from Geosat altimetry
}

\author{
Jiansheng Zou \\ Institut für Meereskunde, Universität Hamburg, Hamburg, Germany \\ Mojib Latif \\ Max Planck Institute für Meteorologie, Hamburg, Germany
}

\begin{abstract}
Satellite-derived (Geosat altimetry) sea surface height anomalies for the period November 1986 to September 1989 were investigated in order to extract the dominant modes of climate variability in the tropical Pacific. We applied the technique of principal oscillation patterns and computed associated wind stress patterns for each mode. Four modes were identified. The first mode has a time scale of about 3 months and can be identified with the first baroclinic equatorial Kelvin wave mode, which is excited by intraseasonal wind variations over the western equatorial Pacific. The second mode has a time scale of about 6 months and describes the semiannual cycle in the tropical Pacific sea level. Equatorial wave dynamics appears to be crucial for this mode also. The third mode is the annual cycle which shows evidence of off-equatorial Rossby wave propagation. The fourth mode is associated with the El Niño/Southern Oscillation (ENSO) phenomenon. The ENSO mode is found to be consistent with the "delayed action oscillator" scenario.
\end{abstract}

\section{Introduction}

The verification and further development of ocean general circulation models depend critically on the availability of adequate forcing and verification data. Also, the application of coupled ocean-atmosphere models to short-range climate predictions requires a good database for properly specifying the initial state of the coupled system. At present, however, there is a significant lack of data, especially over the oceans. Thus satellite-derived data might become more and more important in climate research because the use of satellites is one possible means of obtaining climate data in near-real time in adequate temporal and spatial resolution.

The only satellite-derived oceanic quantity hitherto used routinely to analyze the oceanic state is sea surface temperature (SST) [Reynolds, 1988], but recent studies indicate that other important parameters, such as sea level and surface wind stress, can also be measured with some accuracy from space. Moreover, Picaut et al. [1990] showed that it is also possible to derive low-frequency variations in equatorial Pacific zonal currents from satellite-derived sea levels. Many studies using sea levels from the Geosat mission and focusing on the tropical Pacific [e.g., Tai et al., 1989; Cheney et al., 1989; Cheney and Miller, 1990; White and Tai, 1992; White et al., 1990] have demonstrated the high value of such data in understanding climate variability in this region. The Geosat-derived sea levels, for instance, have been used successfully to describe the variability during the 1986/1987 E1 Niño and the 1988 anti-El Niño phases [e.g., Miller et al., 1987; Miller and Cheney, 1990], and to detect planetary waves [Delcroix et al., 1991]. A summary of studies related to the Geosat mission can be found in a special collection in

Copyright 1994 by the American Geophysical Union.

Paper number 94JC00172.

0148-0227/94/94JC-00172\$05.00 the Journal of Geophysical Research (JGR, 95(C3), 28332836, 1990, and JGR, 95(C10), 17,865-17,876, 1990).

The Geosat data set, the longest available satellite-derived sea level data set, is reanalyzed in this paper using the technique of principal oscillation patterns (POP) [Hasselmann, 1988; von Storch et al., 1988]. The POP technique estimates not only the dominant variability patterns but also their corresponding timescales. The use of such a sophisticated statistical method to analyze the sea level variability is necessary because the different modes in the tropical Pacific do not have well-separated timescales. Thus one cannot distinguish them clearly by considering case studies or applying complex empirical orthogonal functions (CEOF) which average in frequency domain. Despite the short time period covered by the Geosat data set (November 1986September 1989), the set provides a clear description of the different variability modes in the tropical Pacific. Our analysis indicates the existence of at least four modes, an intraseasonal mode, the semiannual cycle, the annual cycle, and an interannual mode with a timescale of about 3 years, the El Niño/Southern Oscillation (ENSO) mode.

This paper is organized as follows: In section 2 the data and the POP technique are described. In section 3 the Geosat sea levels are compared with tide gauge data. Section 4 deals with the results of the POP analysis. The paper is concluded in section 5 .

\section{Data and Statistical Analysis Technique}

\subsection{Processing of the Geosat Data}

The Geosat data used in this study are the so-called T2 Geophysical Data Records (T2-GDR) taken from the Exact Repeat Mission (ERM), covering the time period November 1986 to September 1989. Relative to the original GDRs, the T2-GDRs, described by Cheney et al. [1991] and Miller and 
Table 1. Comparison of the Geosat Sea Levels With the Tide Gauge Data Based on Monthly Mean Values

\begin{tabular}{|c|c|c|c|c|c|}
\hline Islands & Positions & $\sigma \mathrm{t}, \mathrm{cm}$ & $\mathbf{R}$ & $\delta, \mathrm{cm}$ & $\sigma \mathrm{s} / \sigma \mathrm{t}$ \\
\hline Ponape & $7.0 \mathrm{~N}, 158.2^{\circ} \mathrm{E}$ & 11.1 & 0.96 & 4.2 & 0.77 \\
\hline Majuro & $7.1^{\circ} \mathrm{N}, 171.4^{\circ} \mathrm{E}$ & 9.1 & 0.84 & 5.0 & 0.85 \\
\hline Yap & $9.9^{\circ} \mathrm{N}, 138.2^{\circ} \mathrm{E}$ & 11.6 & 0.61 & 9.3 & 0.67 \\
\hline Saipan & $15.2^{\circ} \mathrm{N},, 145.7^{\circ} \mathrm{E}$ & 9.3 & 0.53 & 8.1 & 0.71 \\
\hline Wake & $19.3^{\circ} \mathrm{N}, 166.6^{\circ} \mathrm{E}$ & 9.1 & 0.25 & 9.4 & 0.63 \\
\hline Johnston & $16.7^{\circ} \mathrm{N}, 169.5^{\circ} \mathrm{W}$ & 8.6 & 0.81 & 5.0 & 0.83 \\
\hline Tarawa & $1.4^{\circ} \mathrm{N}, 172.9^{\circ} \mathrm{E}$ & 6.4 & 0.81 & 4.2 & 1.11 \\
\hline Canton & $2.8^{\circ} \mathrm{S}, 171.7^{\circ} \mathrm{W}$ & 7.2 & 0.89 & 4.0 & 1.21 \\
\hline Funafuti & $8.5^{\circ} \mathrm{S}, 179.2^{\circ} \mathrm{E}$ & 9.0 & 0.90 & 3.9 & 0.9 \\
\hline Suva & $18.1^{\circ} \mathrm{S}, 178.4^{\circ} \mathrm{E}$ & 6.2 & 0.23 & 7.5 & 0.94 \\
\hline Penrhyn & $9.0^{\circ} \mathrm{S}, 158.1^{\circ} \mathrm{W}$ & 4.3 & 0.80 & 2.7 & 0.98 \\
\hline Papeete & $17.5^{\circ} \mathrm{S}, 149.6^{\circ} \mathrm{W}$ & 4.1 & 0.65 & 3.9 & 1.22 \\
\hline Christmas & $1.9^{\circ} \mathrm{N}, 157.5^{\circ} \mathrm{W}$ & 12.2 & 0.91 & 5.3 & 0.78 \\
\hline Noumea & $22.3^{\circ} \mathrm{S}, 166.4^{\circ} \mathrm{E}$ & 3.5 & 0.38 & 5.7 & 0.85 \\
\hline Malakal & $7.3^{\circ} \mathrm{N}, 134.5^{\circ} \mathrm{E}$ & 13.6 & 0.51 & 11.5 & 0.60 \\
\hline Kapingamarangi & $1.1^{\circ} \mathrm{N}, 154.8^{\circ} \mathrm{E}$ & 6.6 & 0.77 & 4.5 & 0.97 \\
\hline Nauru & $0.5^{\circ} \mathrm{S}, 166.9^{\circ} \mathrm{E}$ & 7.2 & 0.72 & 5.1 & 0.90 \\
\hline French & $23.9^{\circ} \mathrm{S}, 166.3^{\circ} \mathrm{W}$ & 11.6 & -0.01 & 12.9 & 0.46 \\
\hline Honolulu & $21.3^{\circ} \mathrm{N}, 157.9^{\circ} \mathrm{W}$ & 5.7 & 0.56 & 5.7 & 1.12 \\
\hline Rarotonga & $21.2^{\circ} \mathrm{S}, 160.0^{\circ} \mathrm{W}$ & 7.5 & 0.43 & 7.0 & 0.68 \\
\hline Fanning & $3.9^{\circ} \mathrm{N}, 159.4^{\circ} \mathrm{W}$ & 9.3 & 0.89 & 4.3 & 0.85 \\
\hline Rikitea & $23.1^{\circ} \mathrm{S}, 134.6^{\circ} \mathrm{W}$ & 4.5 & 0.41 & 4.6 & 0.89 \\
\hline Easter & $27.2^{\circ} \mathrm{S}, 109.5^{\circ} \mathrm{E}$ & 4.4 & -0.09 & 6.4 & 0.98 \\
\hline Honiara & $9.4^{\circ} \mathrm{S}, 160.0^{\circ} \mathrm{E}$ & 11.3 & 0.75 & 7.5 & 0.63 \\
\hline Rabaul & $4.2^{\circ} \mathrm{S}, 152.1^{\circ} \mathrm{E}$ & 9.3 & 0.65 & 7.4 & 0.89 \\
\hline Nuku hiua & $8.9^{\circ} \mathrm{S}, 140.1^{\circ} \mathrm{W}$ & 5.6 & 0.72 & 3.6 & 0.75 \\
\hline Chichijima & $27.1^{\circ} \mathrm{N}, 142.2^{\circ} \mathrm{E}$ & 8.1 & 0.03 & 11.2 & 0.99 \\
\hline Midway & $28.2^{\circ} \mathrm{N}, 177.4^{\circ} \mathrm{W}$ & 6.5 & 0.14 & 6.9 & 0.57 \\
\hline Truk & $7.5^{\circ} \mathrm{N}, 151.9^{\circ} \mathrm{E}$ & 6.6 & 0.76 & 4.3 & 0.95 \\
\hline Kwajalein & $8.7^{\circ} \mathrm{N}, 167.7^{\circ} \mathrm{E}$ & 6.6 & 0.85 & 4.6 & 1.30 \\
\hline Santa Cruz & $0.9^{\circ} \mathrm{S}, 90.3^{\circ} \mathrm{W}$ & 8.1 & 0.61 & 6.7 & 0.35 \\
\hline Baltra & $0.43^{\circ} \mathrm{S}, 90.3^{\circ} \mathrm{W}$ & 8.1 & 0.53 & 7.0 & 0.35 \\
\hline
\end{tabular}

Here $\mathrm{R}$ is the correlation, $\delta$ is the RMS error, $\sigma \mathrm{t}$ is the standard deviation of the tide gauge data, and $\sigma s / \sigma t$ is the ratio of the standard deviations of the Geosat and the tide gauge data. The grand average of all correlations amounts to 0.59 .

Cheney [1990], were produced using an improved representation of the satellite orbit and applying more realistic water vapor corrections based on satellite measurements. The satellite orbit was determined using the Goddard Earth Model-T2. The estimation of the water vapor correction is based on measurements with the special sensor microwave imager (SSMI) and the TIROS $\mathrm{N}$ operational vertical

Table 2. Table of Variability Modes Derived From the Geosat Sea Levels

\begin{tabular}{lccc}
\hline \multicolumn{1}{c}{ Mode } & $\begin{array}{c}\text { Rotation } \\
\text { Period }\end{array}$ & $\begin{array}{c}\text { Damping } \\
\text { Time }\end{array}$ & $\begin{array}{c}\text { Explained } \\
\text { Variance, \% }\end{array}$ \\
\hline Intraseasonal mode & 93 & 84 & $13(5)$ \\
Semiannual cycle & 187 & 237 & $29(11)$ \\
Annual cycle & 359 & 594 & $17(20)$ \\
ENSO mode & 1140 & 1023 & $27(25)$ \\
\hline
\end{tabular}

The rotation periods and damping times are given in days. The explained variances are given with respect to the filtered data. Values in brackets denote the explained variances with respect to the raw data computed for the first two years and the region $10^{\circ} \mathrm{N}-10^{\circ} \mathrm{S}$. sounder (TOVS), which operated on satellites contemporaneously with Geosat.

The T2-GDRs are recorded in $1 \mathrm{~s}$ intervals and were processed by us as follows: First, we eliminated spikes from the data. We defined spikes by applying the following two criteria: significant wave height (SWH) larger than $8 \mathrm{~m}$ or standard deviation of ten " 0.1 -second" samples larger than $8 \mathrm{~cm}$. Second, we applied a height correction including (1) ionosphere correction, (2) wet troposphere correction based on SSMI/TOVS data, (3) dry troposphere correction based on the European Centre for Medium-Range Weather Forecasts (ECMWF) model, (4) ocean tide, (5) solid tide, (6) inverse barometer correction, and (7) sea state bias parameterized as $2 \%$ of the SWH.

The altimeter data profiles were taken over the area $50^{\circ} \mathrm{S}$ to $40^{\circ} \mathrm{N}$ and $80^{\circ} \mathrm{E}$ to $50^{\circ} \mathrm{W}$, which is considerably larger than the region of interest and even includes part of the Indian Ocean. The choice of this relatively large domain is important to avoid a damping of oceanic signals with long wavelengths. We used linear functions to fit the satellite radial orbital error. The altimeter along-track sea level deviations were generated using the conventional collinear analysis method [Cheney et al., 1989]. The objective analysis method 

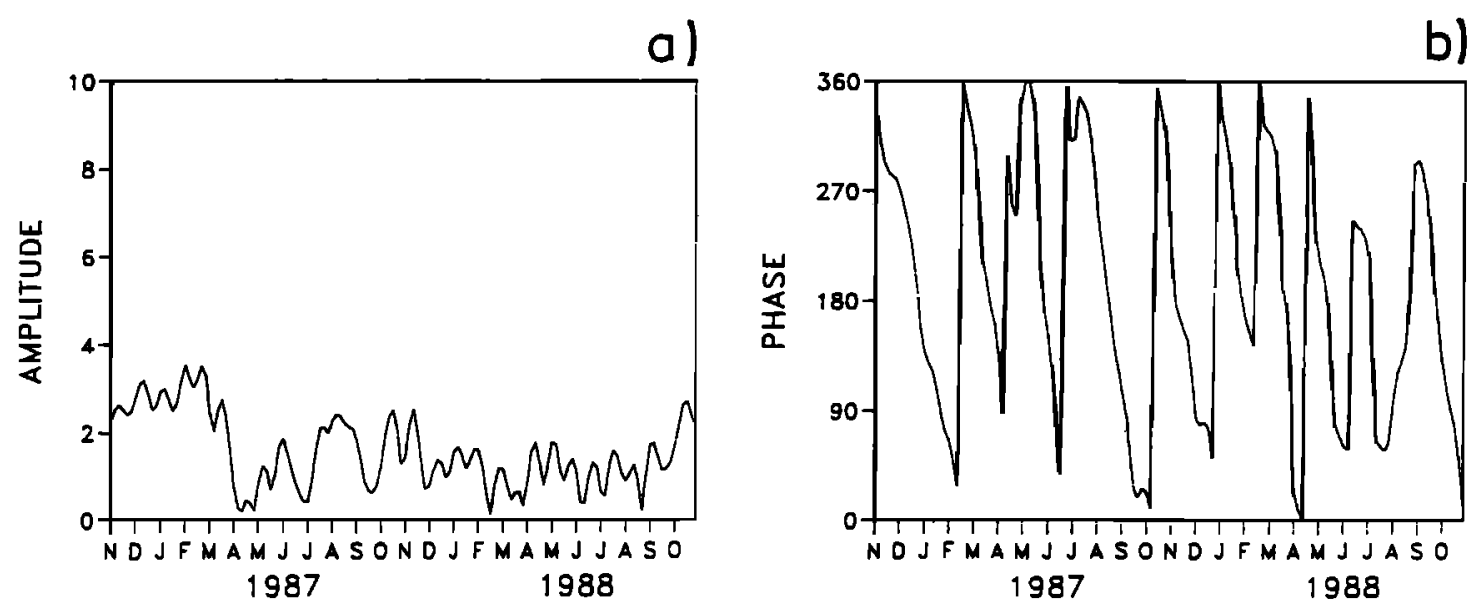

Figure 1. (a) Amplitude and (b) phase time series of the intraseasonal POP mode.

[Bretherton et al., 1976] was applied to interpolate the altimeter along-track data onto a regular grid. Data were constructed for the tropical Pacific and cover the region $20^{\circ} \mathrm{N}-20^{\circ} \mathrm{S}, 120^{\circ} \mathrm{E}-90^{\circ} \mathrm{W}$ on a $2^{\circ}$ (latitude) $\times 5^{\circ}$ (longitude) grid. The chosen time interval is 5 days. Sea level anomalies were computed relative to the January 1987-December 1988 mean.

\subsection{Pseudo Wind Stress Data}

In order to derive the characteristic wind stress patterns which force the sea level variations, associated regression patterns were computed for the surface pseudo wind stress $\tau_{\mathrm{ps}}\left(\tau_{\mathrm{ps}}=|\nu| \cdot \nu\right)$. Instantaneous $1000 \mathrm{hPa}$ winds $\nu$ obtained from the analysis of the ECMWF were used to calculate the pseudo stresses. Pseudo stress fields were averaged in space and time in the same way as the altimeter sea level fields, as described above. Similarly, pseudo stress anomalies were computed as deviations from the January 1987-December 1988 mean.

\subsection{POP Analysis}

Our statistical investigation of the modes of climate variability in the tropical Pacific is based on the method of principal oscillation patterns (POP), which is designed to extract the dominant modes of variability from a multidimensional data set [Hasselmann, 1988; von Storch et al., 1988; Blumenthal, 1991; Latif et al., 1993]. The POPs are the eigenvectors of the system matrix, obtained by fitting the data to a multivariate first-order Markov process. POPs are, in general, complex with a real part $p_{1}$ and an imaginary part $p_{2}$. The corresponding complex coefficient time series satisfy the standard damped harmonic oscillator equation, so that the evolution of the system in the two-dimensional POP space can be interpreted as a cyclic sequence of spatial patterns:

$$
\cdots \rightarrow p_{1} \rightarrow-p_{2} \rightarrow-p_{1} \rightarrow p_{2} \rightarrow p_{1} \rightarrow \cdots
$$

The period to complete a full cycle will be referred to as the "rotation period" and the $e$-folding time for exponential decay as the "damping time." Both timescales are estimated as part of the POP analysis. As described by Hasselmann [1988], the POP technique, as opposed to CEOFs, has the advantage of providing information about the frequency structure of the cross spectrum by identifying the spectral peaks (inverse rotation periods) and peak widths (inverse damping times) associated with different patterns. In order to investigate the spatial characteristics of the wind stress fields which force the sea level variability, associated regression patterns were calculated by simply regressing the components of the pseudo stress vector on the POP coefficient time series.

Prior to the POP analyses, time filtering was applied. Two POP analyses were performed. First, in order to derive variability modes with timescales less than the annual cycle, the Geosat data were band-pass filtered (retaining variability with periods of 1-10 months), and the POP analysis was restricted to the first 2 years and the region $10^{\circ} \mathrm{N}$ to $10^{\circ} \mathrm{S}$ only. Second, a low-pass filter (retaining variability with timescales longer than 3 months) was applied to derive the annual cycle and low-frequency modes from the Geosat data, and the POP analysis was applied to the complete time period and the region $20^{\circ} \mathrm{N}$ to $20^{\circ} \mathrm{S}$.

\section{Comparison With Tide Gauge Data}

We used the tide gauge sea levels described by Wyrtki et al. [1988] to verify the satellite-derived sea levels. These data were used by Latif and Flügel [1991] in a statistical investigation of the low-frequency variability in the tropical Pacific. The altimetric sea levels were interpolated objectively onto the tide gauge locations in order to compare the two data sets. Overall, the altimetric sea levels are highly correlated with the tide gauge data in the region $20^{\circ} \mathrm{N}$ to $20^{\circ} \mathrm{S}$. Correlation coefficients are on the order of 0.8 , while the RMS error does not exceed a few centimeters. Table 1 gives a summary of the verification results. Poleward of $20^{\circ}$ in both hemispheres the results are unsatisfying. Our main focus in this paper, however, is the equatorial region. We therefore restrict ourselves here to the region $20^{\circ} \mathrm{N}$ to $20^{\circ} \mathrm{S}$, where the altimetric sea levels are in excellent agreement with the tide gauge data.

\section{Variability Modes}

We summarize the results of the POP analyses of the Geosat sea levels in Table 2. In order to get an idea of how significant the POP modes are, for each POP mode we computed the explained variance relative to the raw (unfil- 


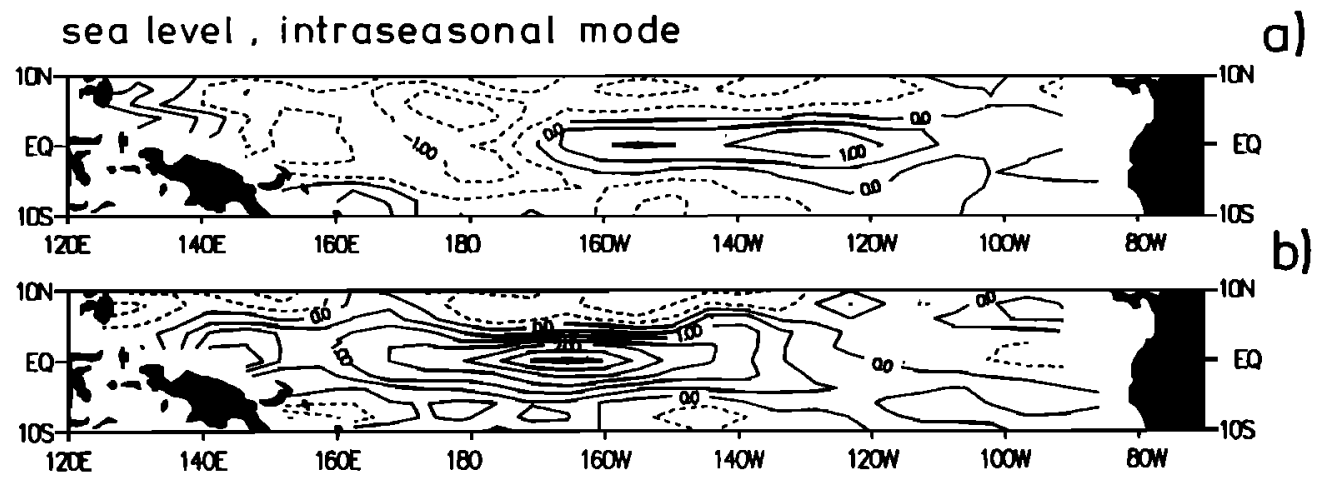

Figure 2. Spatial sea level patterns (in centimeters) of the intraseasonal POP mode. (a) Real part; (b) imaginary part.

\section{$\tau_{P S}^{x}(x, E q ., t)$, intraseasonal mode $\left.b\right)$}

\section{$z(x, E q ., t)$, intraseasonal mode}

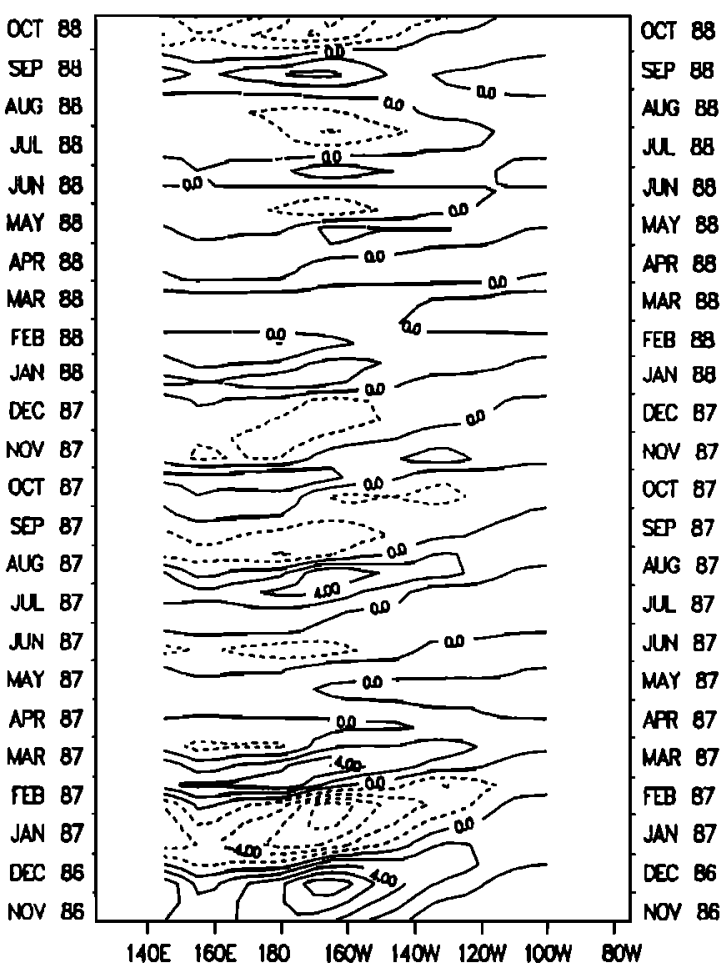

a)

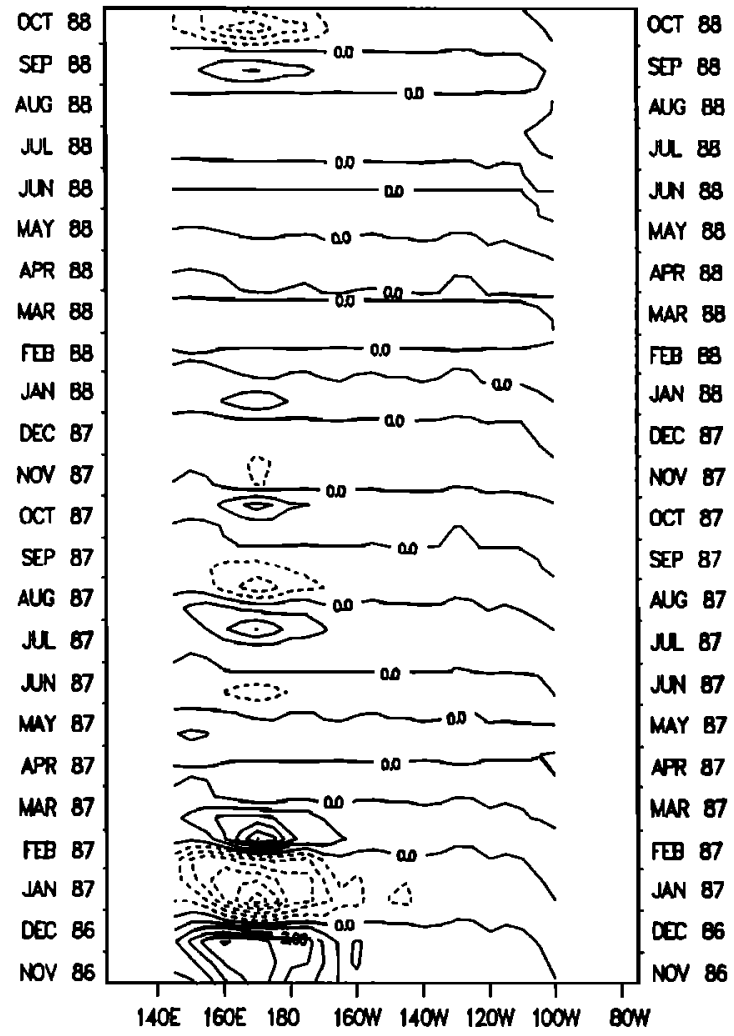

Figure 3. Longitude-time sections of (a) sea level (centimeters) and (b) zonal pseudo wind stress (square meters per square second) along the equator, reconstructed from the intraseasonal POP mode.

$\tau_{\text {PS, intraseasonal mode }}$
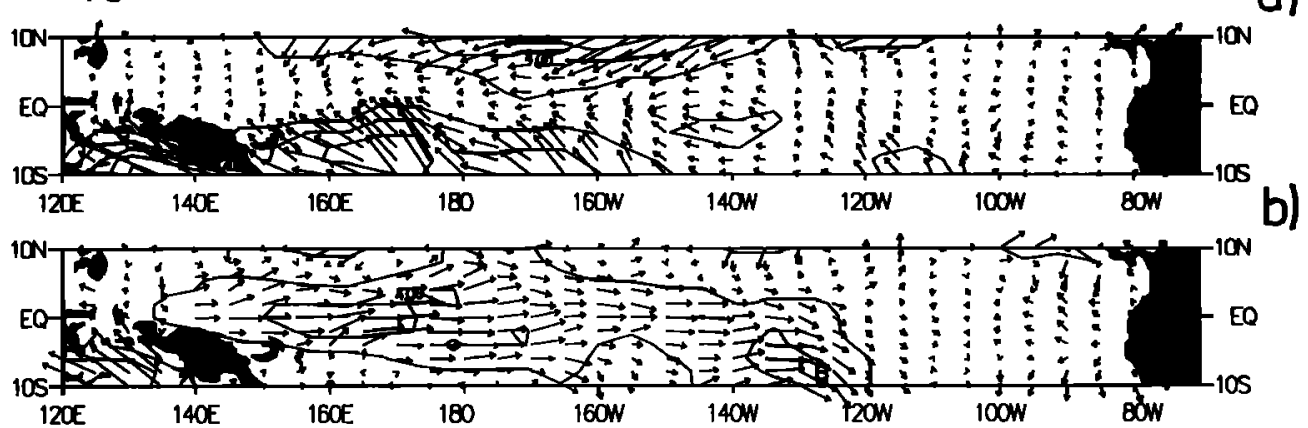

Figure 4. Associated regression patterns of the pseudo wind stress (square meters per square second) on the coefficient time series of the intraseasonal POP mode. (a) Real part; (b) imaginary part. Contours denote the magnitude, and arrows denote the direction. 

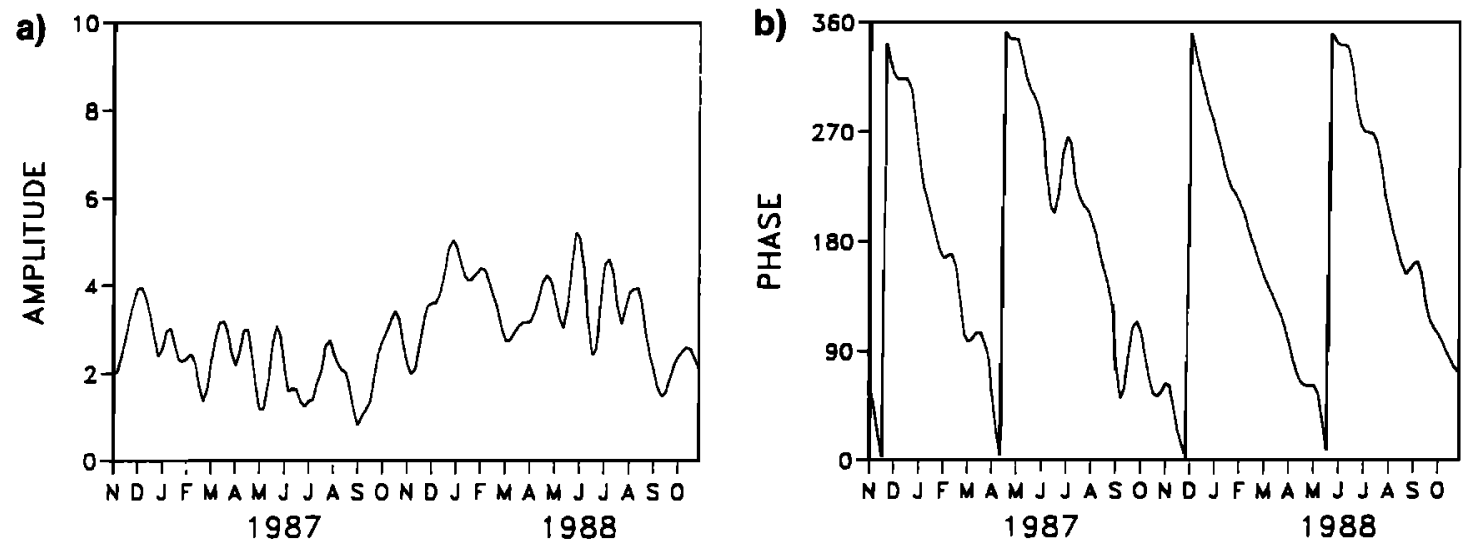

Figure 5. (a) Amplitude and (b) phase time series of the semiannual cycle POP mode.

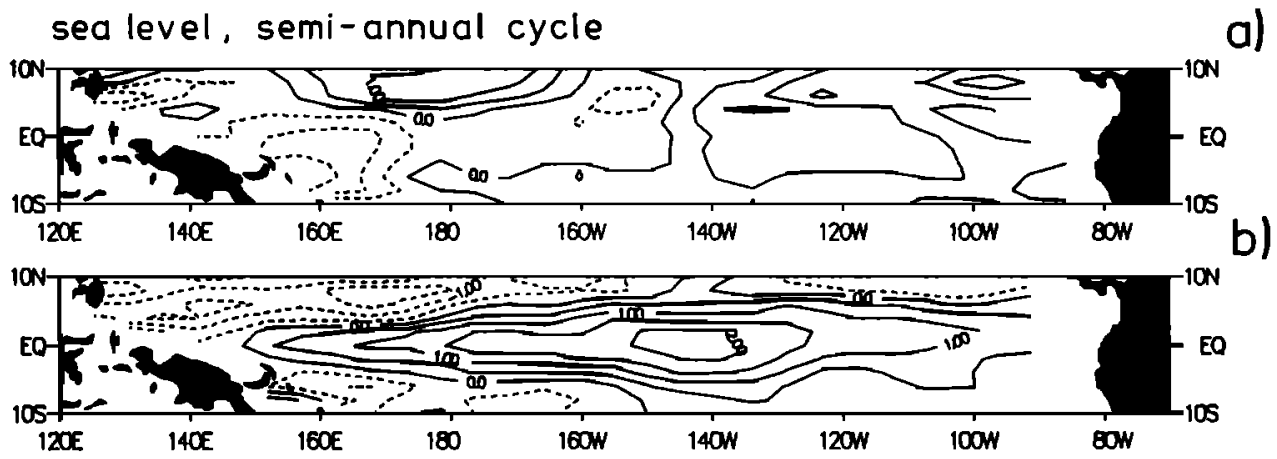

Figure 6. Spatial sea level patterns (centimeters) of the semiannual cycle POP mode. (a) Real part; (b) imaginary part.

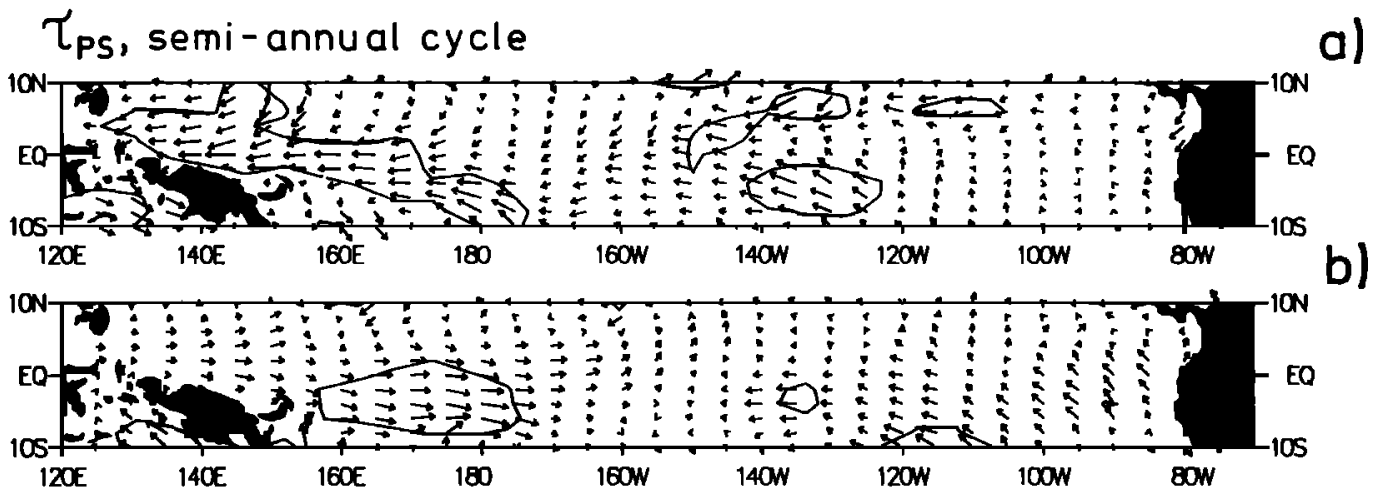

Figure 7. Associated regression patterns of the pseudo wind stress (square meters per square second) on the coefficient time series of the semiannual cycle POP mode. (a) Real part; (b) imaginary part. Contours denote the magnitude, and arrows denote the direction. 
$z(x, E q ., t)$, semi-annual cycle

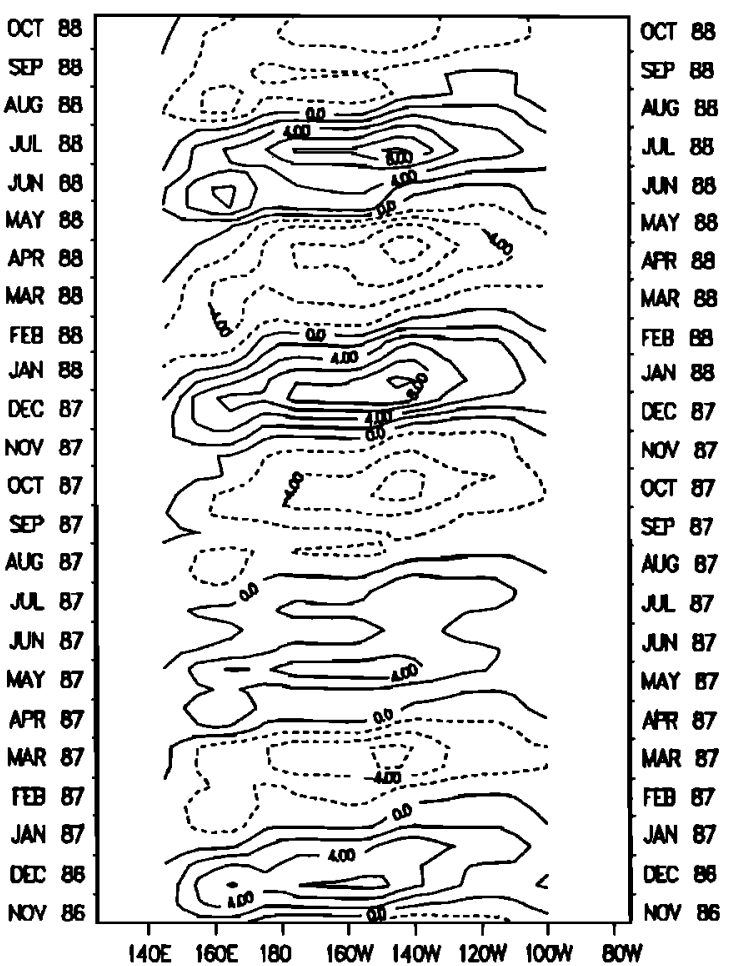

$z\left(x, 6^{\circ} \mathrm{N}, t\right)$, semi-annual cycle

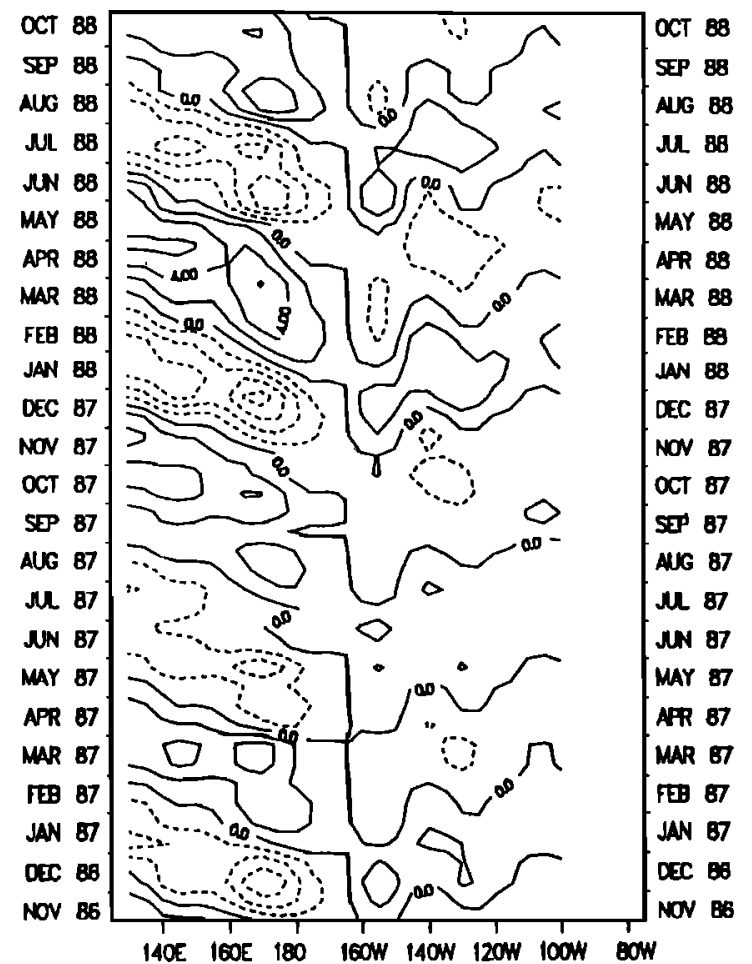

$\tau_{P S}^{x}(x, E q ., t)$, semi-annual cycle b)

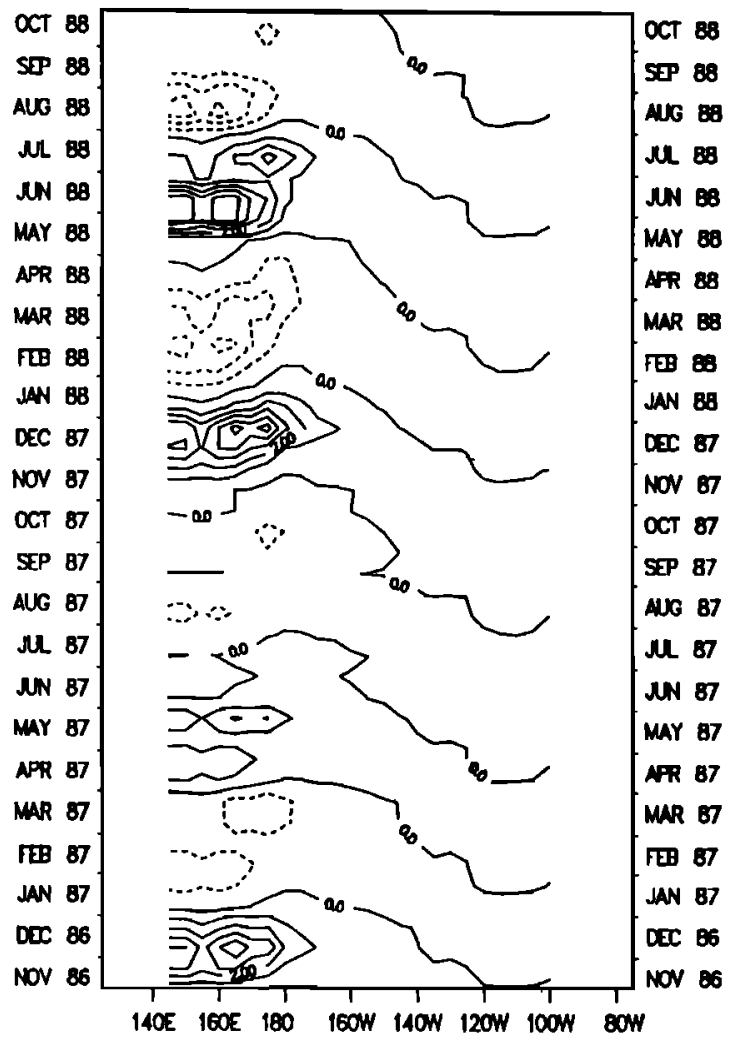

c) $\nabla \times \tau_{P S}\left(x, 6^{\circ} \mathrm{N}, t\right)$, semi-annual cycle

d)

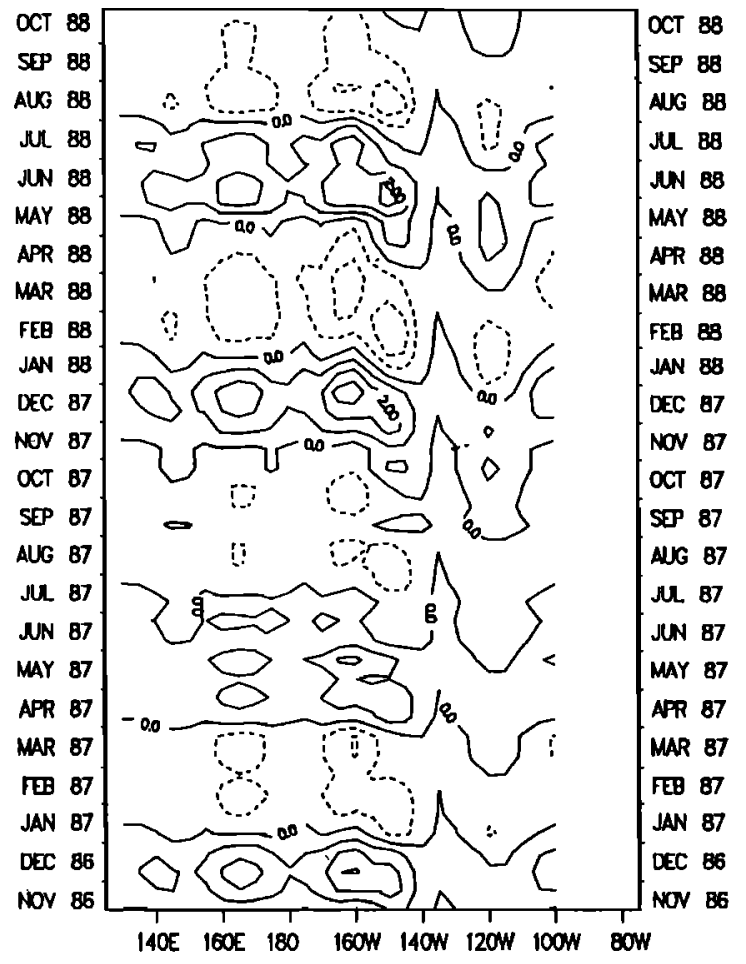

Figure 8. (a) Longitude-time section of sea level (centimeters) at the equator; (b) longitude-time section of zonal pseudo wind stress (square meters per square second) at the equator; (c) longitude-time section of sea level (centimeters) at $6^{\circ} \mathrm{N}$; and (d) longitude-time section of pseudo wind stress curl (square meter per square second per kilometer) at $6^{\circ} \mathrm{N}$, reconstructed from the semiannual POP mode. 

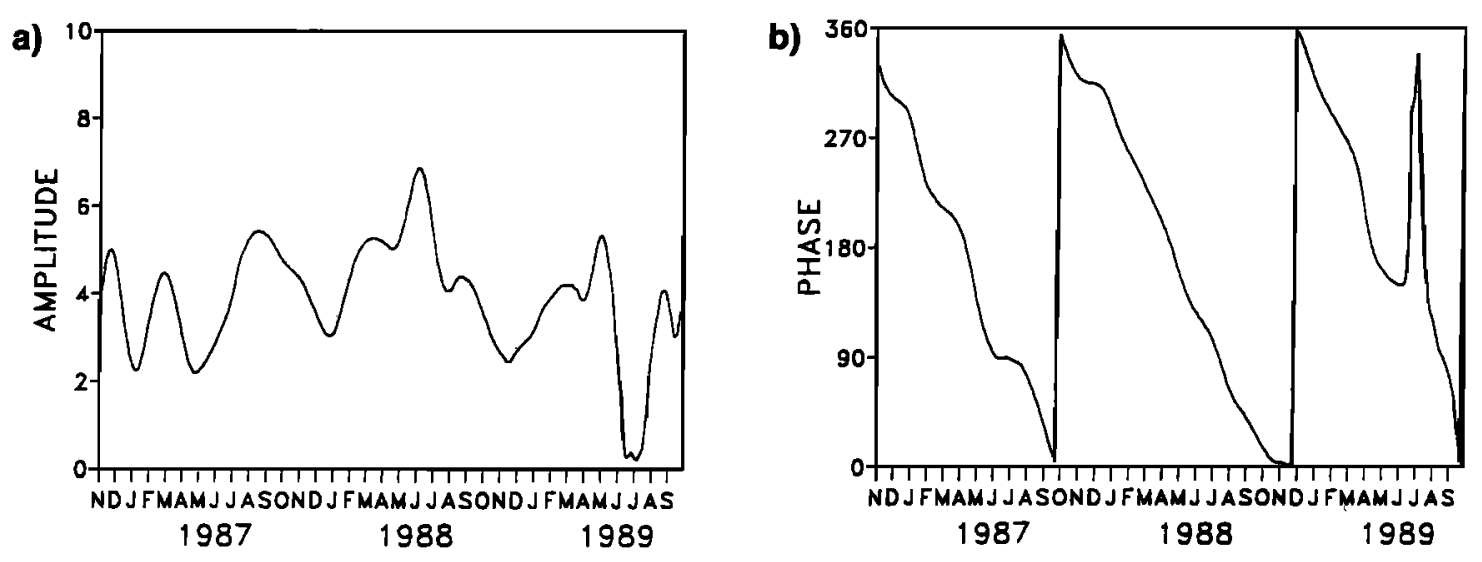

Figure 9. (a) Amplitude and (b) phase time series of the annual cycle POP mode.

tered) data. The four variability modes identified in the Geosat data and described below together explain $47 \%$ of the original variance in the region $10^{\circ} \mathrm{N}-10^{\circ} \mathrm{S}$ during the period November 1986 to October 1988.

\subsection{Intraseasonal Mode}

The highest-frequency mode which was derived from the Geosat sea levels will be referred to as the "intraseasonal" mode. This mode explains $13 \%$ of the variance in the band-pass filtered data (4.5\% in the raw data) and its POP period is 93 days, while the damping time amounts to 84 days. The POP period indicates that this POP mode is the oceanic counterpart of the atmospheric " $30-60$ day" oscillation [Madden and Julian, 1972], but it is still an open question as to why the period of the oceanic oscillation is shifted by about 30 days relative to the atmospheric oscillation. The amplitude time series of the intraseasonal mode (Figure 1a) indicates strongest activity during late 1986 and early 1987, which is consistent with the study of McPhaden et al. [1990]. The phase time series of the intraseasonal mode (Figure 1b) is fairly regular, with about 10 cycles during the analyzed period November 1986 to October 1988.

The two POP patterns (Figure 2), consistent with equatorial Kelvin wave dynamics, exhibit equatorially trapped signals which propagate eastward along the equator with a speed of about $2.5 \mathrm{~m} / \mathrm{s}$. This is clearly seen in a longitudetime section of sea level anomalies reconstructed from the POP mode (Figure 3a). We conclude that this particular POP mode can be identified with the first baroclinic Kelvin wave mode which has a similar theoretical phase speed. This is supported by the case study of Miller et al. [1987], who also found evidence of Kelvin wave propagation when analyzing the original Geosat altimeter data.

The associated regression pattern of the pseudo stress field (Figure 4) on the (complex) POP time series shows a strong westerly anomaly centered in the western equatorial Pacific near $160^{\circ} \mathrm{E}$ which lasts for a few weeks only (Figure 4b). Such wind events in the western Pacific are related to the atmospheric " $30-60$ day" oscillation and referred to as "wind bursts." The response of the equatorial Pacific to these wind bursts is described in several studies in which in situ observations were analyzed [e.g., McPhaden et al., 1988; McPhaden and Hayes, 1990], and the results described in these studies are consistent with our findings. In particular, our results support the picture that on intraseasonal timescales, sea level variability in the central and eastern Pacific is remotely forced by wind anomalies in the western Pacific. This can be inferred from the longitude-time section of equatorial zonal pseudo stresses (Figure $3 \mathrm{~b}$ ) which shows significant stress anomalies over the western Pacific only.

\subsection{Semiannual Cycle}

The next POP mode considered, which explains $29 \%$ of the variance in the band-pass filtered data $(10 \%$ in the raw data), has a rotation period of 187 days, i.e., about 6 months, and a damping time of about 8 months. This mode represents the semiannual cycle in the equatorial Pacific sea level, as can be seen clearly from the POP phase time series (Figure 5b). The POP patterns show the well-known characteristics of equatorial waves (Figures $6 a$ and $6 b$ ). We therefore hypothesize that this mode represents the forced wave response of the equatorial Pacific to the semiannual component of the surface wind stress. The imaginary part (Figure 6b) is consistent with Rossby wave activity in the western Pacific and Kelvin wave activity in the eastern Pacific, with maximum anomalies off the equator in the west and at the equator in the east. Western boundary Rossby wave reflection is evident in the rotation from the imaginary (Figure 6b) to the real part (Figure 6a), which shows a signal emanating from the western boundary and propagating eastward along the equator. The associated regression patterns of the wind stress field (Figure 7) show strong signals over the western and central equatorial Pacific only. This is the region where the semiannual cycle in the wind stress has considerable amplitude [Goldenberg and O'Brien, 1981; Horel, 1982].

The wave nature of this mode is also shown by longitudetime sections of the sea level, associated wind stress and wind stress curl reconstructions (Figure 8). The reconstructed sea level anomalies at the equator show a distinct eastward propagation (Figure 8a) away from the forcing region in the western Pacific (Figure $8 b$ ). Off-equatorial sea level anomalies at $6^{\circ} \mathrm{N}$ are characterized by westward propagation (Figure 8c), while the wind stress curl at $6^{\circ} \mathrm{N}$ is dominated by a standing component (Figure 8d). A similar behavior is found at $6^{\circ} \mathrm{S}$ (not shown). The estimated phase speed of sea level anomalies at $6^{\circ} \mathrm{N}$ amounts to about $0.8 \mathrm{~m} / \mathrm{s}$ and that at the equator to about $2.5 \mathrm{~m} / \mathrm{s}$. Both values are consistent with the theoretical estimates of the leading baroclinic equatorial wave mode that involves the first meridional mode Rossby wave, which has a phase speed of 
sea level, annual cycle
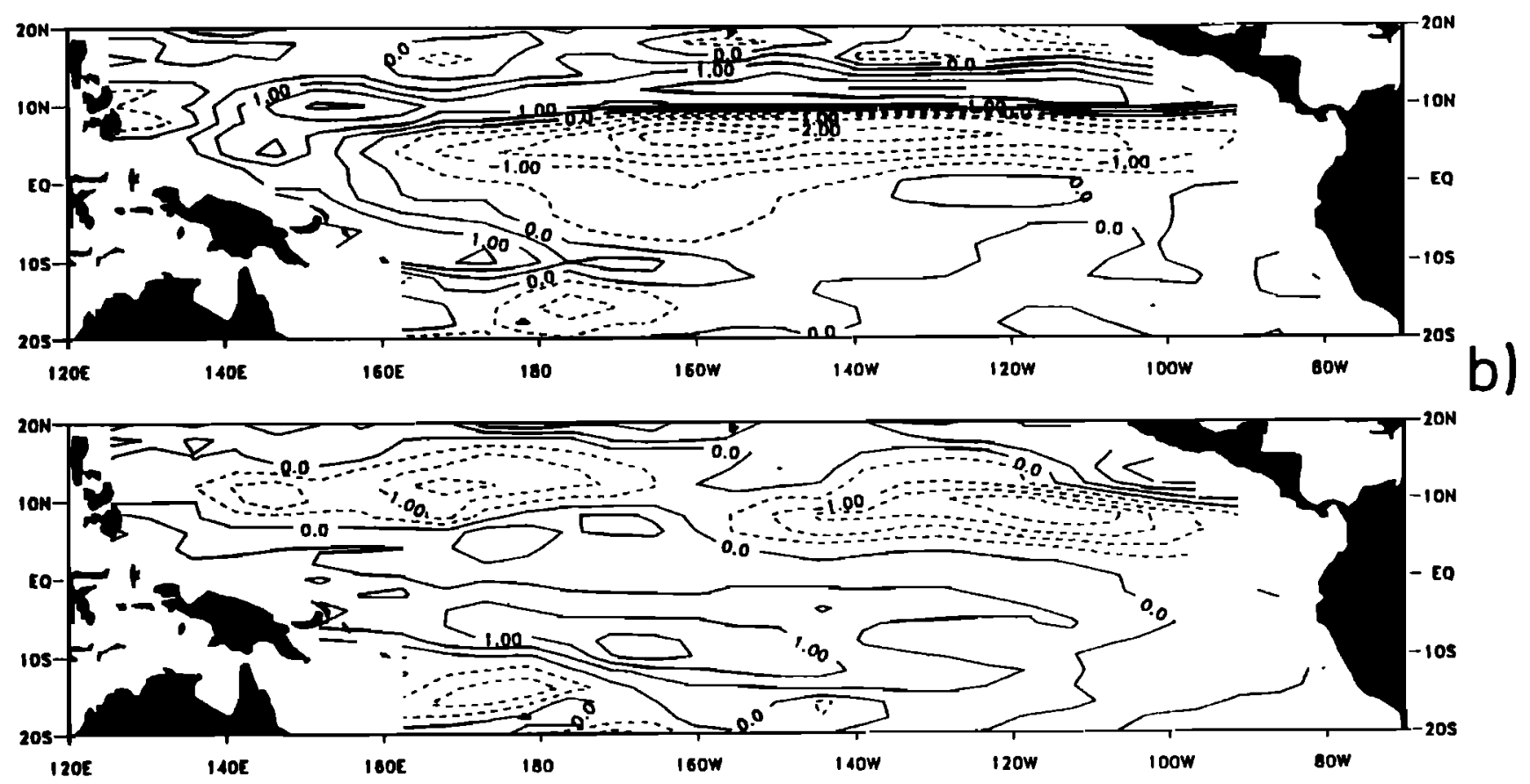

Figure 10. Spatial sea level patterns (centimeters) of the annual cycle POP mode. (a) Real part; (b) imaginary part.

about one third of the Kelvin wave speed. Western boundary wave reflection of the Rossby wave into a Kelvin wave can also be inferred from the longitude-time sections of the reconstructed sea level anomalies at $6^{\circ} \mathrm{N}$ and at $0^{\circ}$ (Figures $8 \mathrm{a}$ and $8 \mathrm{c}$ ). Thus the semiannual sea level variability at the equator consists of a locally forced and a remotely forced component.

\subsection{Annual Cycle}

We next low-pass filtered the data, extended the analysis to the region $20^{\circ} \mathrm{N}$ to $20^{\circ} \mathrm{S}$, and considered the full time period in order to derive the annual cycle and low-frequency variability. The annual cycle accounts for $17 \%$ of the sea level variability in the low-pass filtered Geosat data. The

\section{$\tau_{P S}$, annual cycle}
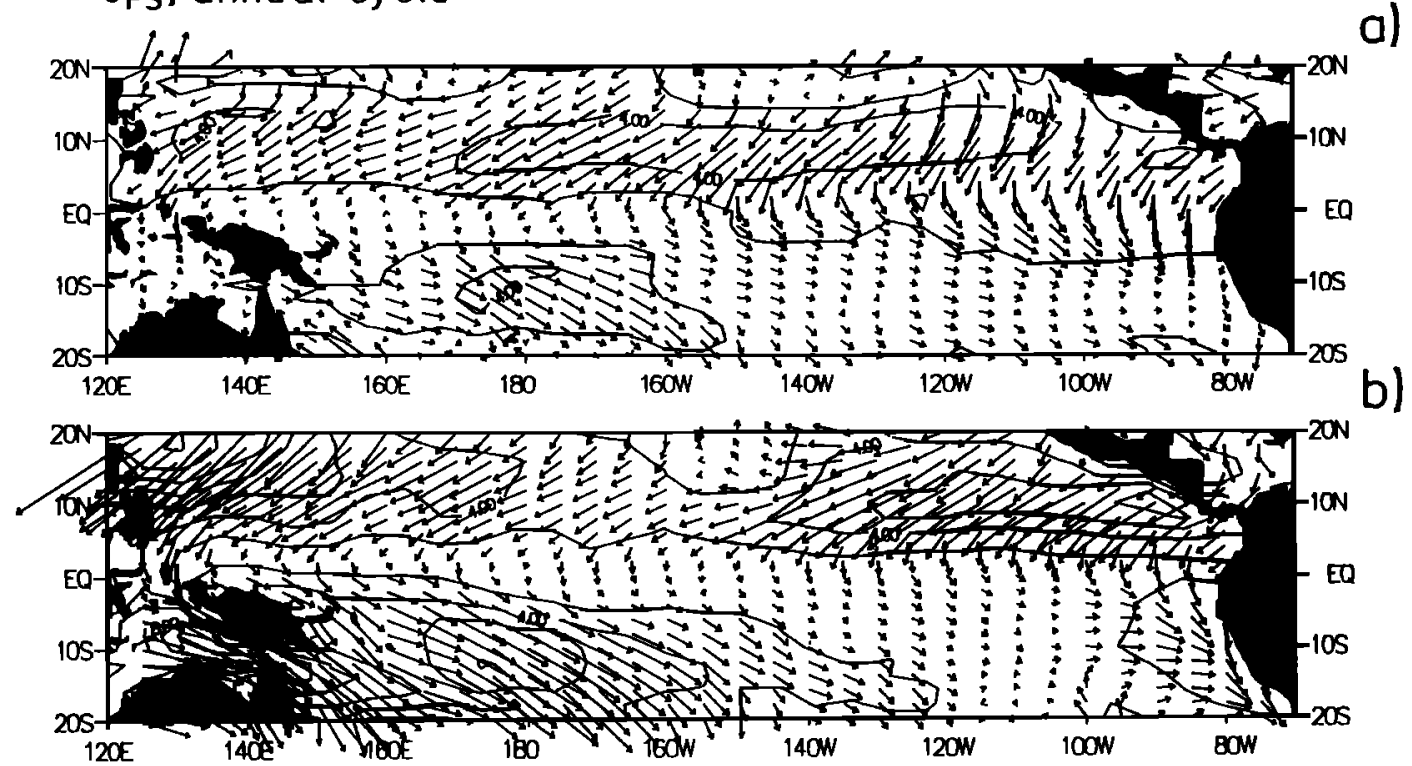

Figure 11. Associated regression patterns of the pseudo wind stress (square meters per square second) on the coefficient time series of the annual cycle POP mode. (a) Real part; (b) imaginary part. Contours denote the magnitude, and arrows denote the direction. 
$z(x, E q ., t)$, annual cycle

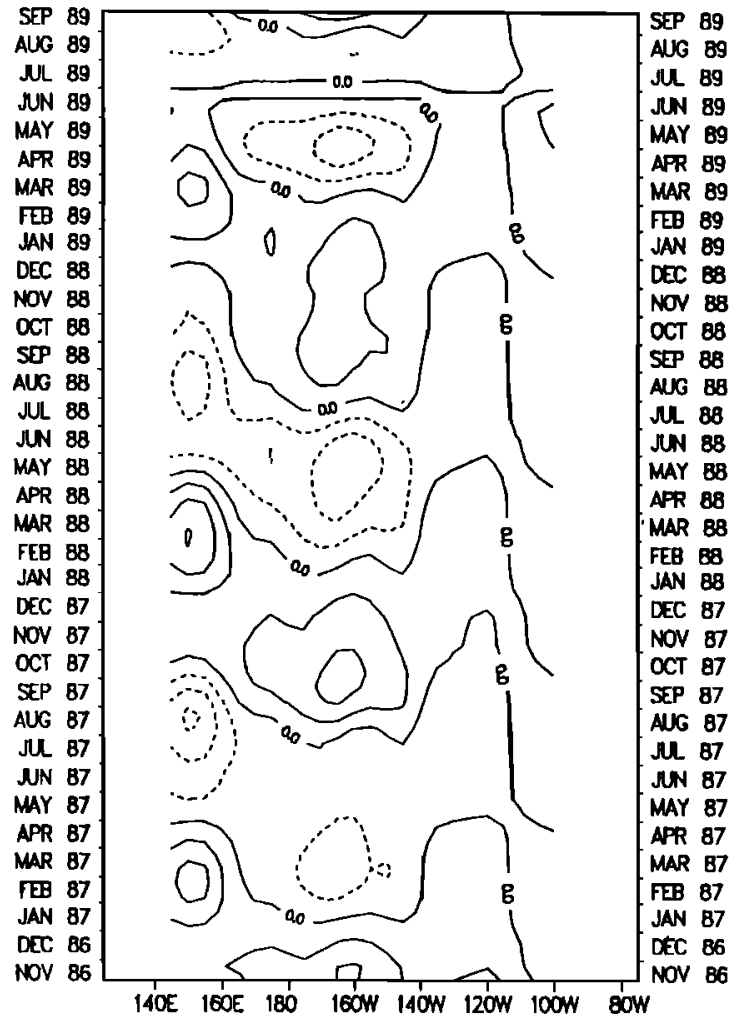

$\nabla_{x} \tau_{P S}\left(x, 6^{\circ} \mathrm{N}, t\right)$, annual cycle

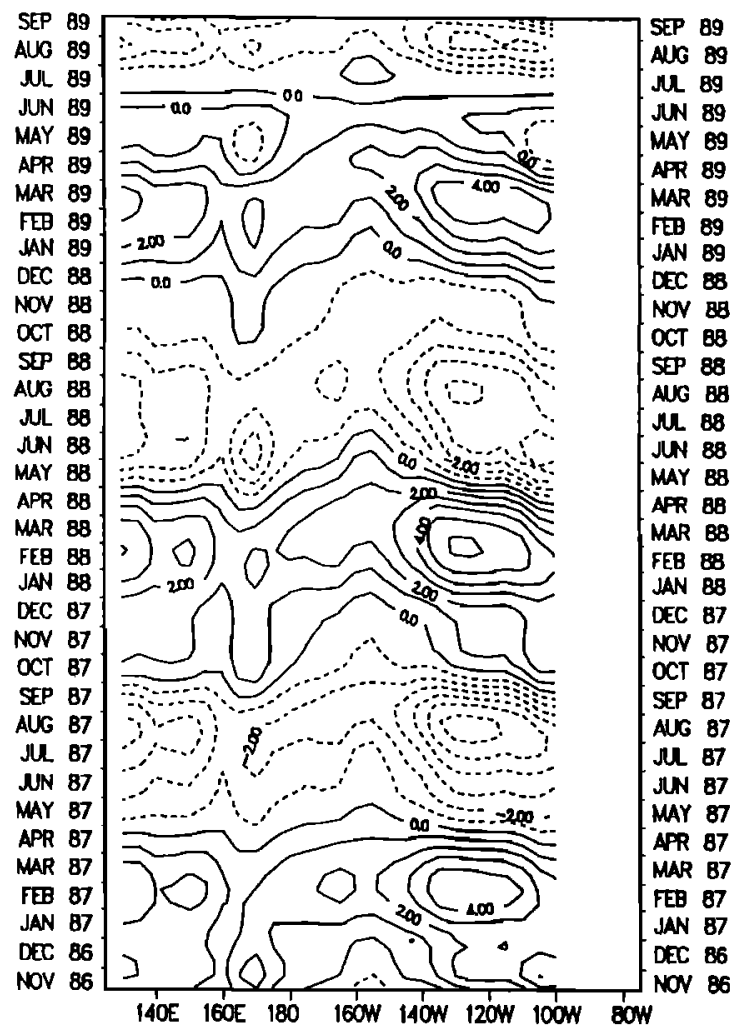

$z\left(x, 6^{\circ} \mathrm{N}, t\right)$, annual cycle

b)

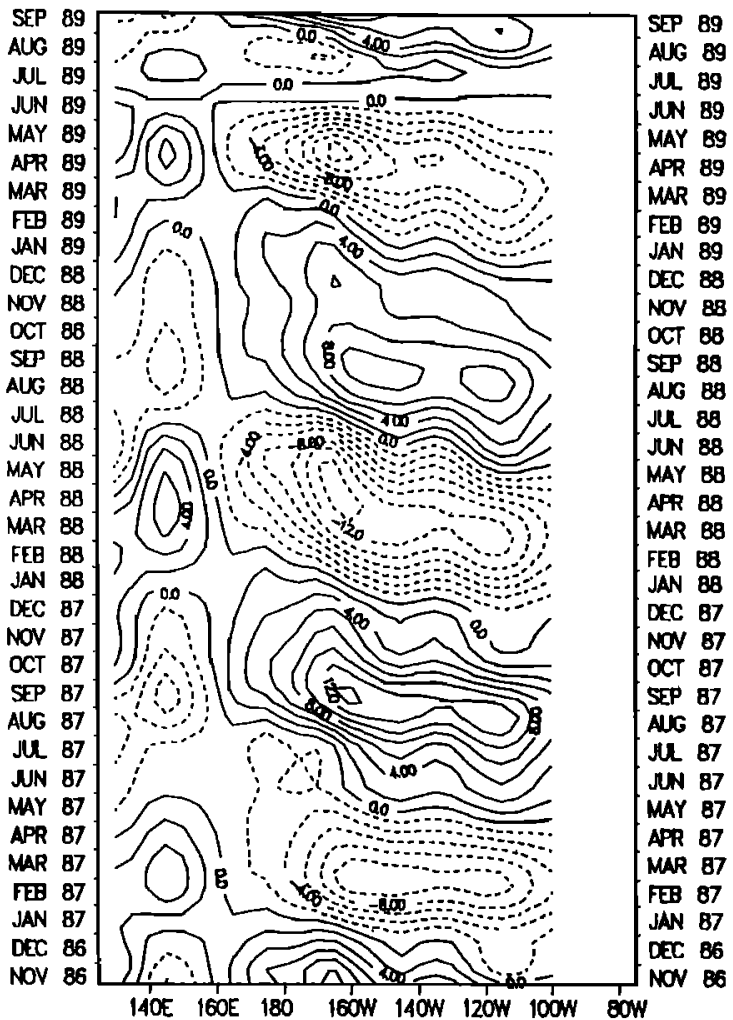

$z\left(x, 6^{\circ} \mathrm{S}, t\right)$, annual cycle

d)

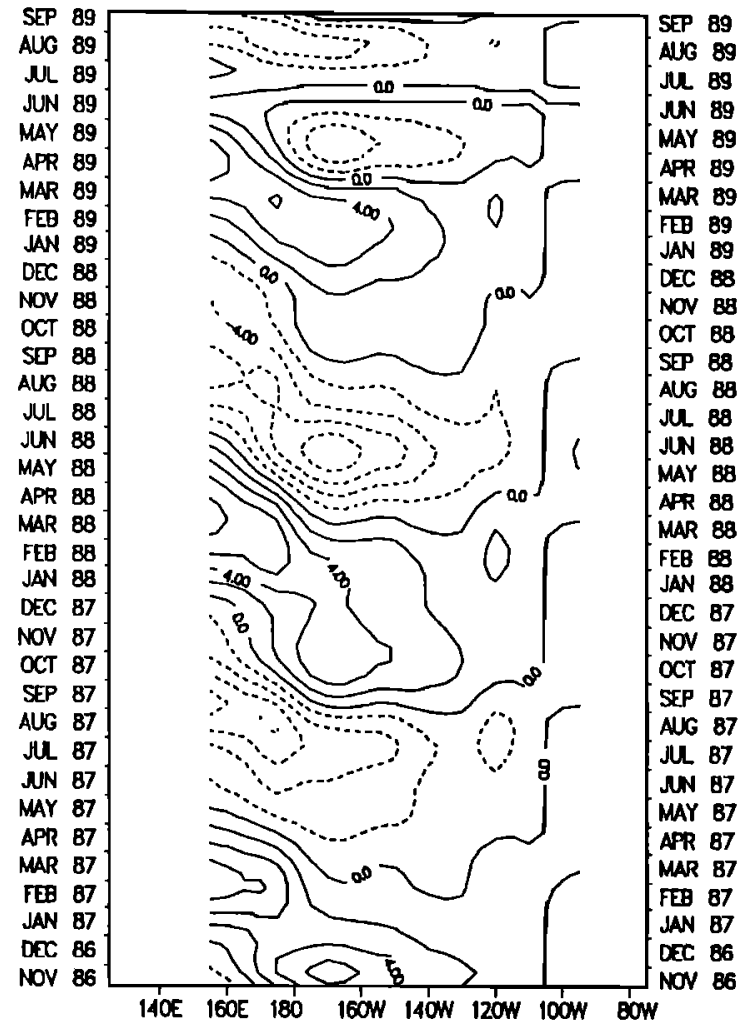

Figure 12. (a) Longitude-time section of sea level (centimeters) at the equator, (b) longitude-time section of sea level (centimeters) at $6^{\circ} \mathrm{N}$, (c) longitude-time section of pseudo wind stress curl (square meters per square second per kilometer) at $6^{\circ} \mathrm{N}$, (d) longitude-time section of sea level (centimeters) at $6^{\circ} \mathrm{S}$, and (e) longitude-time section of pseudo wind stress curl (square meters per square second per kilometer) at $6^{\circ} \mathrm{S}$, reconstructed from the annual cycle POP mode. 
$\nabla \times \tau_{P S}\left(x, 6^{\circ} S, t\right)$, annual cycle

e)

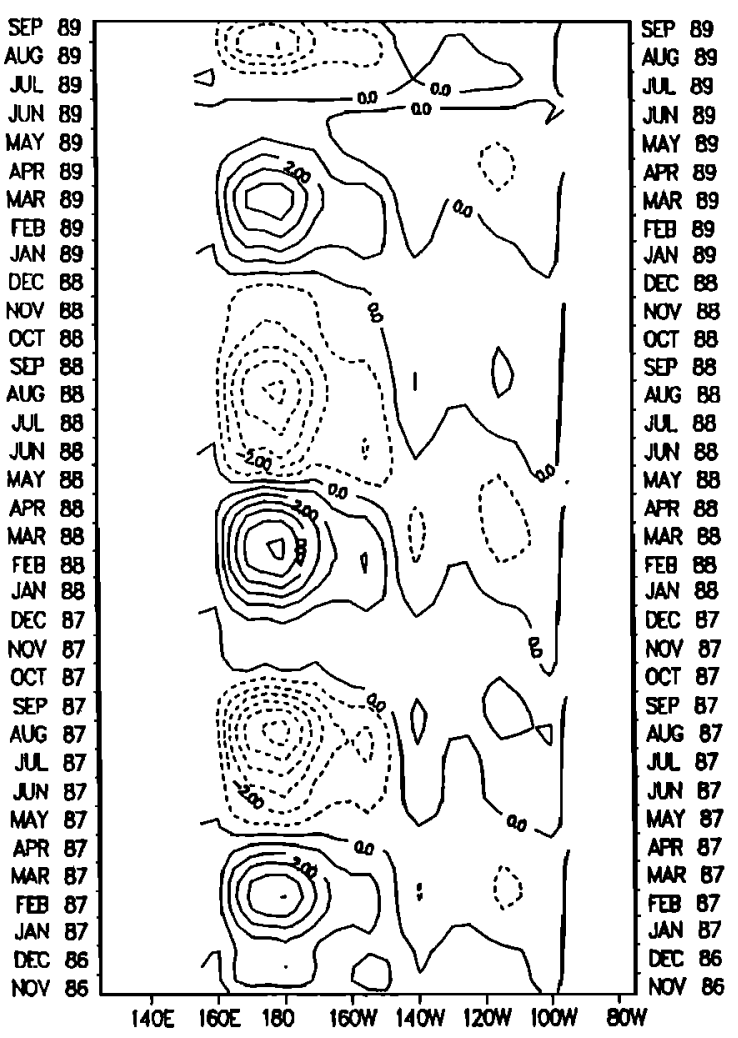

Figure 12. (continued)

POP period is estimated as 359 days and the damping time as 594 days. The POP phase time series (Figure 9b) indicates a fairly regular evolution of the annual cycle throughout the analyzed period, while the POP amplitude time series is rather constant during the first 2 years (Figure 9a). The annual variability in sea level is strongest in the vicinity of the two major convergence zones (Figure 10). In the northern hemisphere, changes are due to the seasonal migration of the Intertropical Convergence Zone, whereas annual variability in the southwestern Pacific is associated with movements of the South Pacific Convergence Zone (Figure 11).
We display longitude-time sections of sea level, associated wind stress, and wind stress curl reconstructed from the annual cycle POP mode in Figure 12. The annual sea level variability off the equator is dominated by Rossby wave propagation. At both latitudes displayed $\left(6^{\circ} \mathrm{N}\right.$ and $\left.6^{\circ} \mathrm{S}\right)$ pronounced westward propagation is observed (Figures $12 \mathrm{~b}$ and 12d), in accordance with the study of Delcroix et al. [1991]. The estimated phase speeds of about $0.5 \mathrm{~m} / \mathrm{s}$ are consistent with Rossby wave propagation at these latitudes and are comparable to those given by Kessler [1990], who investigated off-equatorial Rossby wave propagation using the depth of the $20^{\circ} \mathrm{C}$-isotherm data. The Rossby waves are predominantly excited by changes in the wind stress curl in the eastern Pacific at $6^{\circ} \mathrm{N}$ (Figure 12c), while those at $6^{\circ} \mathrm{S}$ are excited by wind stress curl changes in the central Pacific (Figure 12e). We note an abrupt phase shift in sea level at $6^{\circ} \mathrm{N}$ near $160^{\circ} \mathrm{E}$ (Figure 12b). As discussed by Delcroix et al. [1991], the data coverage is poor in this region so that this feature is not very reliable. At the equator, annual sea level variability is generally weak (Figure 12a). No evidence is found in the Geosat data for annual western boundary Rossby wave reflection, in contrast to the study by White et al. [1990]. The longitude-time section of the sea level at the equator, reconstructed from the annual cycle POP mode, even shows some evidence for westward propagation.

\subsection{ENSO Mode}

Finally, the interannual sea level variability is investigated. The dominant mode of interannual variability in the tropical Pacific is the El Niño/Southern Oscillation (ENSO), which has a preferred recurrence timescale of about 4 years. However, recent observational and theoretical studies indicate that several timescales are involved in ENSO, a predominant biennial timescale and one on the order of 4 years [e.g., Rasmusson et al., 1990; Barnett, 1991; Münnich et al., 1991]. Although the Geosat data set is certainly not long enough to adequately address the ENSO-related interannual variability, the analyzed period is nevertheless suitable for obtaining some insight into the nature of low-frequency variability because it contains a major warm phase (1987) and a major cold phase (1988) of the ENSO cycle.

One interannual POP mode was found that explains about $27 \%$ of the variance in the low-pass filtered data. This mode
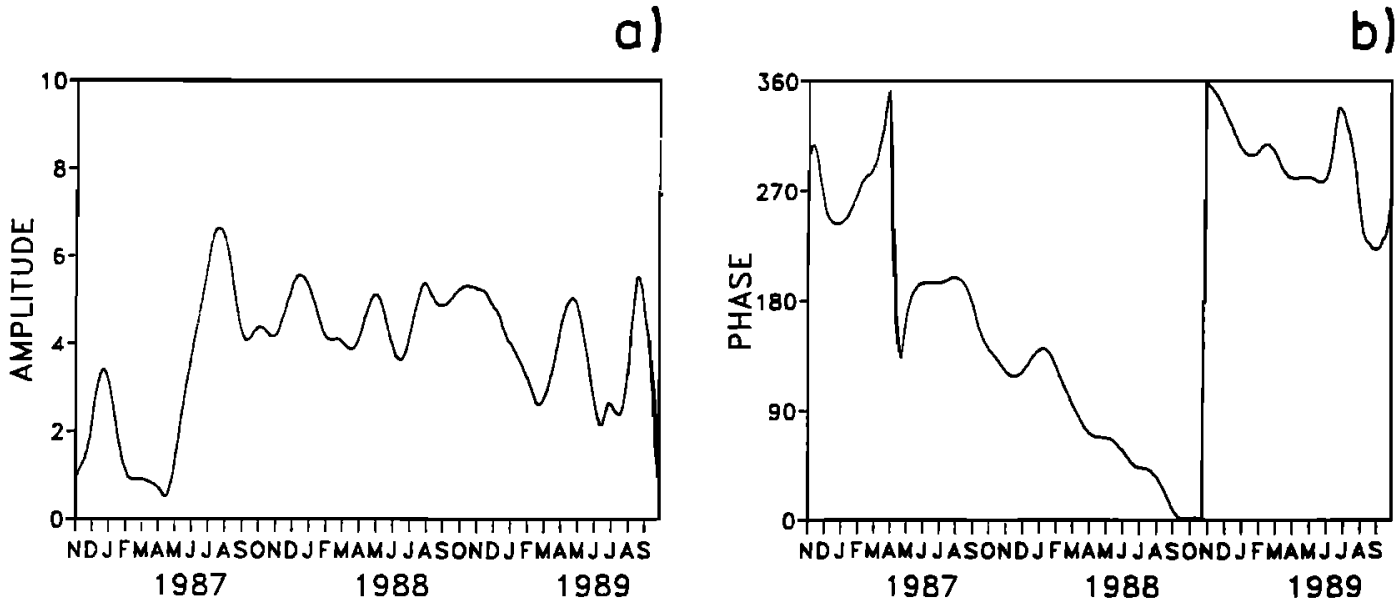

Figure 13. (a) Amplitude and (b) phase time series of the ENSO POP mode. 


\section{sea level, ENSO mode}
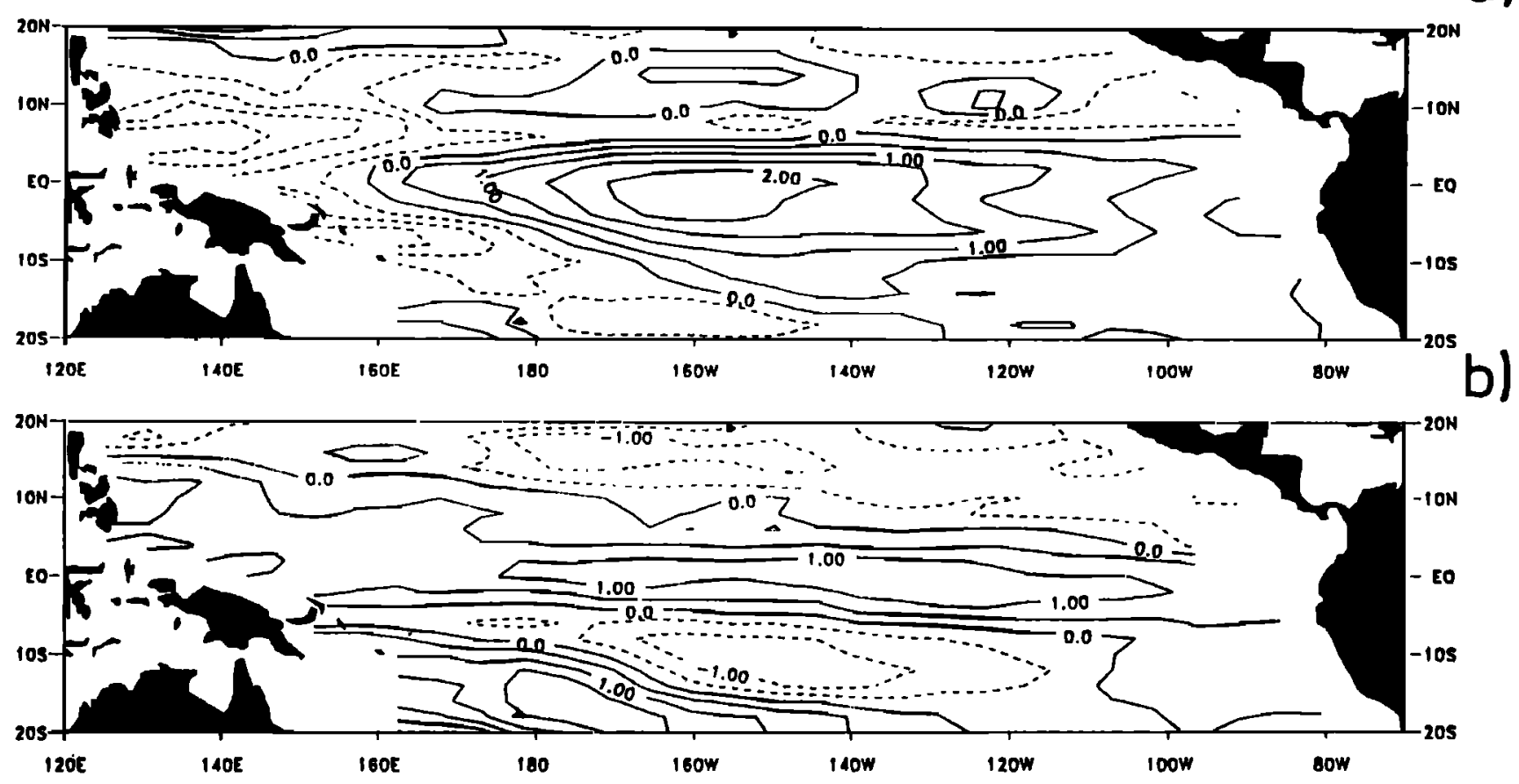

Figure 14. Spatial sea level patterns (centimeters) of the ENSO POP mode. (a) Real part; (b) imaginary part.

is clearly associated with the ENSO phenomenon and has a rotation period of 38 months and a damping time of 34 months. We would like to note, however, that timescale estimates of the ENSO mode are subject to large uncertainties because of the rather short record length. A similar low-frequency POP mode was derived from the island sea levels [Latif and Flügel, 1991]. We display in Figure 13 the POP amplitude and phase time series, in Figure 14 the POP patterns and in Figure 15 the associated regression patterns of the pseudo wind stress. The real part (Figure 14a) represents the conditions during the extreme phases of ENSO (El Niño and La Niña), when SST anomalies are fully developed in the eastern and central equatorial Pacific, and ocean and atmosphere interact strongly, as evidenced by the strong equatorial wind stress anomalies over the western and central Pacific (Figure 15a). The imaginary part (Figure 14b) shows conditions during the transition phases, when equatorial SST and wind stress anomalies are near normal, and ocean-atmosphere coupling is of minor importance (Figure 15b). The transition phase precedes the extreme phase by several months, so that it can be regarded as a precursor pattern. ENSO extremes are preceded by an equatorially trapped signal in sea level (Figure 14b). The meridional extent of this precursor is much smaller than that hypothesized by Wyrtki [1985]. Our result, however, is consistent with the model study of Springer et al. [1990], who identified serious sampling problems in Wyrtki's [1985] work.

Equatorial sea level and zonal wind stress anomalies reconstructed from the ENSO POP mode are displayed as longitude-time sections in Figure 16. The evolution of the anomalous conditions, as derived from the Geosat data set, is consistent with theoretical and observational studies. Sea level anomalies in the eastern and western equatorial Pacific are not exactly out of phase, best seen during the summers of
1987 and 1988 , and this small departure from the $180^{\circ}$ phase lag characterizes the oceanic memory which is so important to interannual variability [Cane and Sarachik, 1981; Neelin et al., 1994]. The low-level wind anomalies are governed by a standing component. These findings are consistent with the conceptual model of "delayed action oscillation" [Schopf and Suarez, 1988; Graham and White, 1988; Chao and Philander, 1993; Latif et al., 1993], but the Geosat record is certainly not long enough to adequately address the dynamics of the interannual variability.

\section{Conclusions}

Sea levels derived from satellite altimetry (Geosat) were investigated for the period November 1986 to September 1989 in order to derive the dominant modes of climate variability in the tropical Pacific. Although the Geosat data set is rather short, it provides a proper modal decomposition of climate variability in the tropical Pacific. The sea level variability in the tropical Pacific can be mainly described in terms of four modes, an intraseasonal mode, the semiannual and annual cycles, and the $\mathrm{El} \mathrm{Niño/Southern} \mathrm{Oscillation}$ (ENSO) mode.

The intraseasonal and semiannual modes can be viewed as the forced ocean responses to variations in equatorial zonal wind stress. Equatorial wave dynamics is crucial for these two modes. The annual cycle shows evidence of offequatorial Rossby wave propagation. Western boundary Rossby wave reflection, however, was not found in the Geosat data. The ENSO mode dominates the variability on interannual timescales. Although the Geosat record is very short, it was possible to extract from it a mode that shares similarities with the "delayed action oscillator" scenario and is consistent with theoretical, observational, and model 

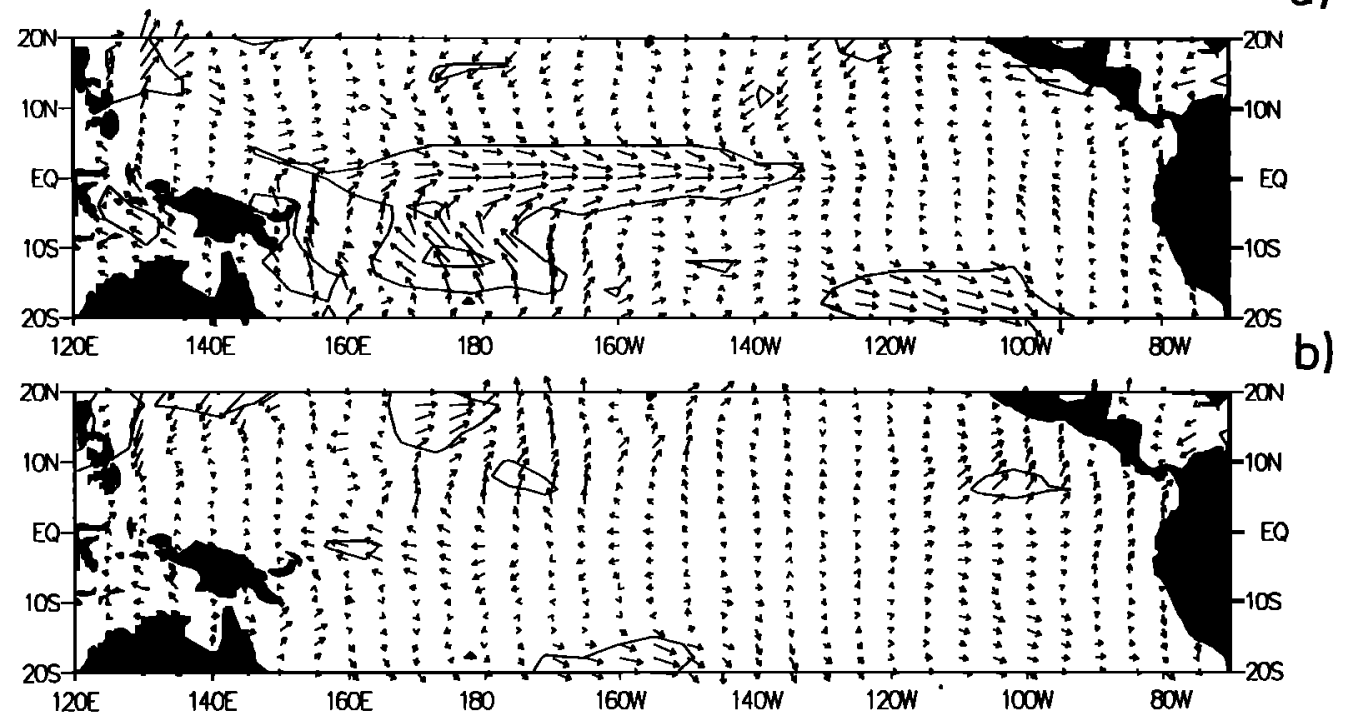

Figure 15. Associated regression patterns of the pseudo wind stress (square meters per square second) on the coefficient time series of the ENSO POP mode. (a) Real part; (b) imaginary part. Contours denote the magnitude, and arrows denote the direction.

studies [e.g., Blumenthal, 1991; Cane and Sarachik, 1981; Chao and Philander, 1993; Graham and White, 1988; Latif and Flügel, 1991; Latif et al., 1993; Neelin et al., 1994].

This study has shown that satellite-derived sea level data contain a large amount of useful information, which can be used to continuously monitor the ocean. Furthermore, the satellite data are highly consistent with the output of an oceanic general circulation model, as discussed by Chao et $z(x$, Eq., $t)$, ENSO mode

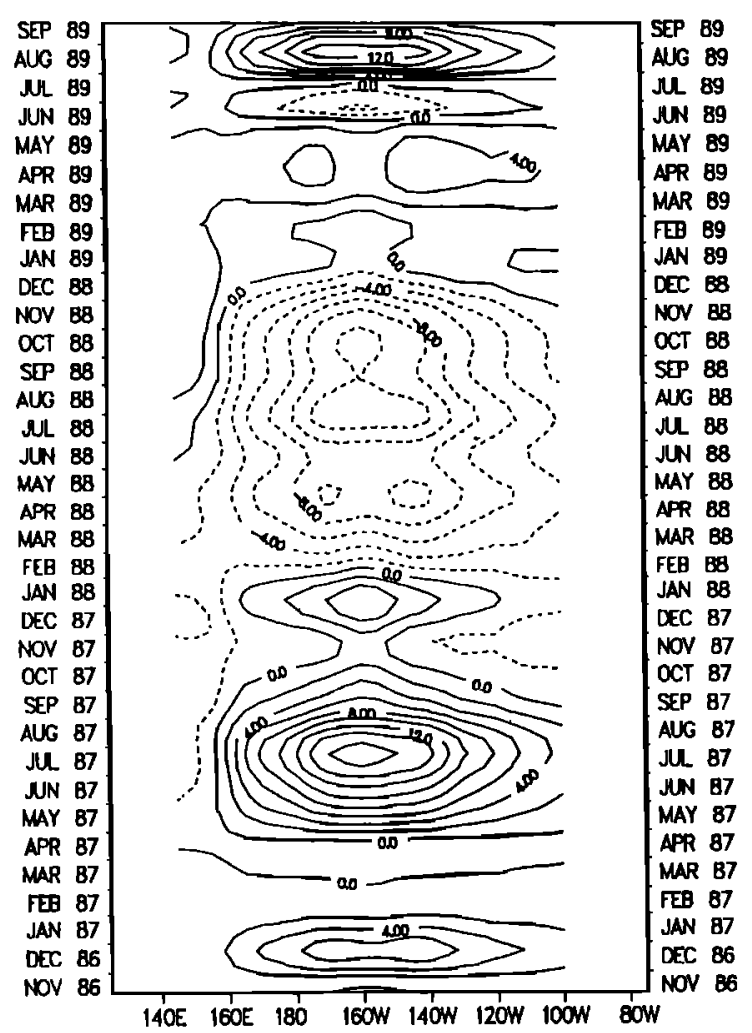

$\tau_{P S}^{x}(x, E q ., t)$, ENSO mode

b)

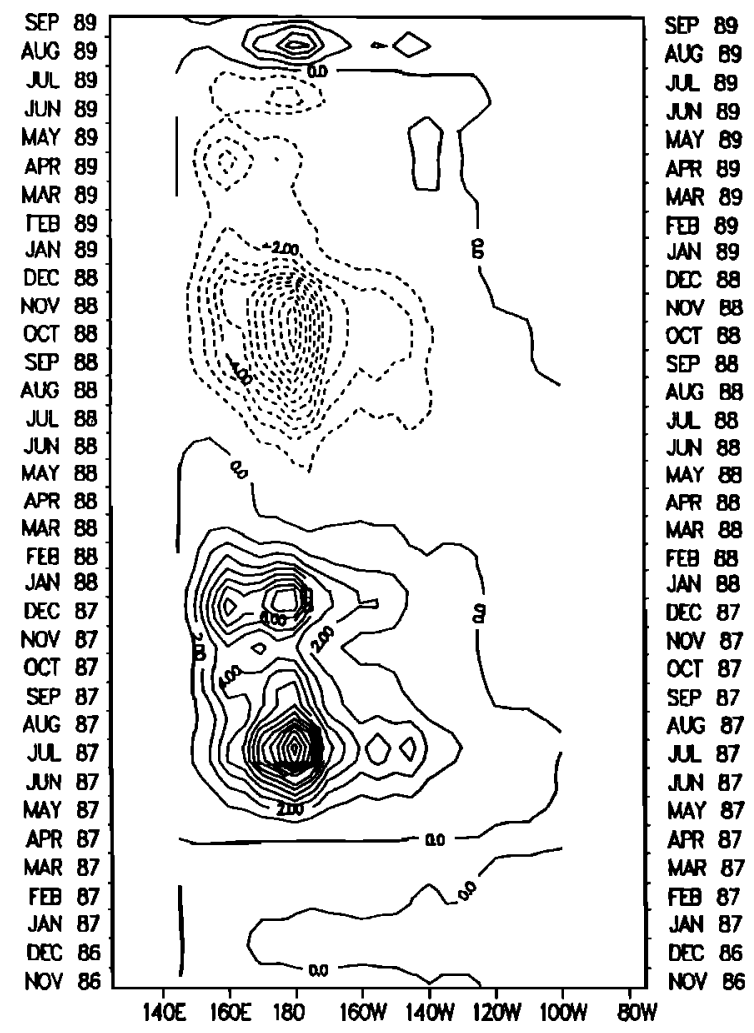

Figure 16. Longitude-time sections of (a) sea level (centimeters) and (b) zonal pseudo wind stress (square meters per square second) along the equator, reconstructed from the ENSO POP mode. 
al. [1993], so that the benefit of the satellite measurements can be maximized by assimilating them into ocean circulation models. In the next stage, the analyzed ocean fields can be used as initial conditions for short-range climate predictions. This work is now underway and will be described in a forthcoming paper.

Acknowledgments. The authors would like to thank W. Alpers for his substantial contribution to this project and E. Maier-Reimer and $H$. von Storch for many fruitful discussions. We thank R. E. Cheney for providing the Geosat data and K. Arpe for providing the wind data. The help of Rainer Schnur in using the POP package is greatly acknowledged. We would like to thank the two anonymous reviewers for their valuable suggestions. Many thanks to $M$. Grunert for preparing the diagrams. This work was supported by the Bundesmimisterium für Forschung und Technologie under grant 07 KFT 31/7 and by the European Community under grant EV5V CT92-0121.

\section{References}

Barnett, T. P., The interaction of multiple time scales in the tropical climate system, J. Clim., 4, 269-285, 1991.

Barnett, T. P., M. Latif, E. Kirk, and E. Roeckner, On ENSO physics, J. Clim., 4, 487-515, 1991.

Blumenthal, M. B., Predictability of a coupled ocean-atmosphere model, J. Clim., 4, 766-784, 1991.

Bretherton, F. P., R. E. Davis, and C. B. Fandry, A technique for objective analysis design of oceanographic experiments applied to mode 73, Deep Sea Res., 23, 559-582, 1976.

Cane, M. A., and E. S. Sarachik, The response of a linear baroclinic equatorial ocean to periodic forcing, J. Mar. Res., 39, 651-693, 1981

Chao, Y., and S. G. H. Philander, On the structure of the Southern Oscillation, J. Clim., 6, 450-469, 1993.

Chao, Y., D. Halpern, and C. Perigaud, Sea surface height variability during 1986-1988 in the tropical Pacific Ocean, J. Geophys. Res., 98(C4), 6947-6959, 1993.

Cheney, R. E., and L. Miller, Recovery of the sea level signal in the western tropical Pacific from Geosat altimetry, J. Geophys. Res. 95(C3), 2977-2984, 1990 .

Cheney, R. E., B. C. Douglas, and L. Miller, Evaluation of Geosat altimeter data with application to tropical Pacific sea level variability, J. Geophys. Res., 94(C4), 4737-4747, 1989.

Cheney, R. E., W. J. Emery, B. J. Haines, and F. Wentz, Recent improvements in Geosat altimeter data, Eos Trans. $A G U, 72(51)$, 577-580, 1991.

Delcroix, T., J. Picaut, and G. Eldin, Equatorial Kelvin and Rossby waves evidenced in the Pacific Ocean through Geosat sea level and surface current anomalies, J. Geophys. Res., 96, suppl., 3249-3262, 1991.

Goldenberg, S. O., and J. J. O'Brien, Time and space variability of tropical Pacific wind stress, Mon. Weather Rev., 109, 1190-1207, 1981 .

Graham, N. E., and W. B. White, The El Niño cycle: A natural oscillator of the Pacific ocean-atmosphere system, Science, 240, 1293-1302, 1988.

Hasselmann, K., PIPs and POPs: The reduction of complex dynamical systems using principal interaction and oscillation patterns, $J$. Geophys. Res., 93(D9), 11,015-11,021, 1988.

Horel, J. D., On the annual cycle of the tropical Pacific atmosphere and ocean, Mon. Weather Rev., 110, 1863-1878, 1982.

Kessler, W. S., Observations of long Rossby waves in the northern tropical Pacific, J. Geophys. Res., 95(C4), 5183-5217, 1990.

Latif, M., and M. Flügel, An investigation of short-range climate predictability in the tropical Pacific, J. Geophys. Res., 96, 26612673, 1991.

Latif, M., A. Sterl, E. Maier-Reimer, and M. M. Junge, Structure and predictability of the El Niño/Southern Oscillation phenomenon in a coupled ocean-atmosphere general circulation model, $J$. Clim., 6, 700-708, 1993.

Madden, R. A., and P. R. Julian, Description of global-scale circulation cells in the tropics with a 40-50 day period, J. Atmos. Sci., 24, 1109-1123, 1972.

McPhaden, M. J., and S. P. Hayes, Variability in the eastern equatorial Pacific Ocean during 1986-1988, J. Geophys. Res., 95(C8), 13,195-13,208, 1990.

McPhaden, M. J., H. P. Freitag, S. P. Hayes, B. A. Taft, Z. Chen, and $\mathbf{K}$. Wyrtki, The response of the equatorial Pacific Ocean to a westerly wind burst in May 1986, J. Geophys. Res., 93(C9), $10,589-10,603,1988$.

McPhaden, M. J., S. P. Hayes, L. J. Magnum, and J. M. Toole, Variability in the western Pacific Ocean during the 1986-87 El Niño/Southern Oscillation event, J. Phys. Oceanogr., 20, 190208, 1990.

Miller, L., and R. E. Cheney, Large-scale meridional transport in the tropical Pacific Ocean during the 1986-1987 El Niño from Geosat, J. Geophys. Res., 95(C10), 17,905-17,919, 1990.

Miller, L., R. E. Cheney, and B. C. Douglas, Geosat altimeter observations of Kelvin waves and the 1986-1987 El Niño, Science, 239, 52-54, 1987.

Münnich, M., M. A. Cane, and S. E. Zebiak, A study of self-excited oscillations of the tropical ocean-atmosphere system, II, Nonlinear cases, J. Atmos. Sci., 48, 1238-1248, 1991.

Neelin, J. D., M. Latif, and F. F. Jin, Dynamics of coupled ocean atmosphere models: The tropical problem, Annu. Rev. Fluid Mech., 26, 617-659, 1994

Picaut, J., A. J. Busalacchi, M. J. McPhaden, and B. Camusat, Validation of the geostrophic method for estimating zonal currents at the equator from Geosat altimeter data, J. Geophys. Res., 95(C3), 3015-3024, 1990.

Reynolds, R. W., A real-time global sea surface temperature analysis, J. Clim., 1, 75-86, 1988.

Rasmusson, E. M., X. Wang, and C. F. Ropelewski, The biennia component of ENSO variability, J. Mar. Syst., 1, 71-96, 1990.

Schopf, P. S., and M. J. Suarez, Vacillations in a coupled oceanatmosphere model, J. Atmos. Sci., 45, 549-566, 1988.

Springer, S. R., M. J. McPhaden, and A. J. Busalacchi, Oceanic heat content variability in the tropical Pacific during the 1982-1983 El Niño, J. Geophys. Res., 95(C12), 22,089-22,101, 1990.

Tai, C. K., W. B. White, and S. E. Pazan, GEOSAT crossover analysis in the tropical Pacific, 2, Verification analysis of altimetric sea level maps with expendable bathythermograph and island sea level data, J. Geophys. Res., 94(C1), 897-908, 1989.

von Storch, H., T. Bruns, I. Fischer-Bruns, and K. Hasselmann, Principal oscillation pattern analysis of the 30- to 60-day oscillation in a general circulation model equatorial troposphere, $J$. Geophys. Res., 93(D9), 11,022-11,036, 1988.

White, W. B., and C. K. Tai, Reflection of interannual Rossby waves at the maritime western boundary of the tropical Pacific, $J$. Geophys. Res., 97(C9), 14,305-14,322, 1992.

White, W. B., N. Graham, and C. K. Tai, Reflection of annual Rossby waves at the maritime western boundary of the tropical Pacific, J. Geophys. Res., 95(C3), 3101-3116, 1990.

Wyrtki, K., Water displacements in the Pacific and the genesis of $\mathrm{El}$ Niño cycles, J. Geophys. Res., 90(C4), 7129-7132, 1985.

Wyrtki, K., K. Constantine, B. J. Kilonsky, G. Mitchum, B. Miyamoto, T. Murphy, S. Nakahara, and P. Caldwell, The Pacific island sea level network, Data Rep. 002, Joint Inst. for Mar. and Atmos. Res., Univ. of Hawaii, Honolulu, 1988.

M. Latif, Max Planck Institut für Meteorologie, Bundestrasse 55, D-20146 Hamburg, Federal Republic of Germany.

J. Zou, Institut für Meereskunde, Universitat Hamburg, Troplowitzstrasse 7, D-22529, Hamburg, Federal Republic of Germany.

(Received September 29, 1993; revised January 14, 1994; accepted January 14, 1994.) 